\title{
Institutional racism in mental health services does not imply racism in individual psychiatrists: Commentary on ... Institutional racism in psychiatry ${ }^{\dagger}$
}

The Mental Health Act Commission has been actively involved in promoting improved mental healthcare for Black and minority ethnic groups for many years. The Commission's First Biennial Report 1983-85 (Mental Health Act Commission, 1985) highlighted our concerns about the over-representation of patients from Black and minority ethnic communities in mental healthcare, and our concerns have not diminished over the years.

In 1997 we conducted our first national visit to 104 units to investigate a number of practice issues in race equality (Warner et al, 2000; Patel et al, 2003). We examined 504 patient files from Black and minority ethnic groups, and interviewed 104 chief executives and 119 senior ward staff. The evidence from this first national visit and that provided by the National Mental Health and Learning Disability Ethnicity Census 2006 'Count Me In' (Healthcare Commission, 2007) almost a decade later indicates that the proportion of people from Black and minority ethnic groups admitted to and detained in mental health services is much higher than we would expect.

No one has yet provided an adequate explanation for the very high rates of admission and detention for some of these groups - notably for Black African, Black Caribbean and Black Other (Black British) people. There are, without doubt, many factors involved. The Count Me In Census 2006 confirmed the findings of the 2005 Census and was broadly aligned with other research (e.g. Bhui et al, 2003). Black groups were between 3 and 5 times more likely to be admitted to psychiatric hospitals than the average. Most worryingly, second-, or probably third-generation Black people who identify themselves as Black British (the Black Other group) were 14 times more likely to be admitted (for men almost 18 times). These figures are statistically significant - out of 32000 patients identified in the 2005 Count Me In Census over 600 identified themselves as Black Other. Additional evidence, such as that emerging from the 'Delivering Race Equality' community engagement programme, suggests worrying trends that young Muslim men (also born in this country) may be experiencing similar problems.

In essence, Professors Singh and Murray and Dr Fearon claim that psychiatry and psychiatrists are being accused of racism, but they appear to misunderstand the concept of institutional racism and dismiss the legitimate concerns of the Black community. We have yet to find recent articles that charge psychiatrists or psychiatry with racism. Professor Singh suggests that it is 'disingenuous to claim that institutional racism is understood at the level of the clinical encounter by anyone in any sense other than as overt, racist discrimination'. But is that not itself the height of disingenuity? The claim of institutional racism, by definition, is not directed at the level of the individual clinical encounter but at the organisational complex we refer to as mental health services, which includes hospital and related community services. However, Professor Singh does understand one manifestation of institutional racism because he describes the 'risks that many from minority ethnic groups face... of not being given the correct diagnosis . . . because of their ethnicity.'

Professor Singh obfuscates the argument when he says that by 'focusing inappropriately on culture and ethnicity at the expense of sound clinical judgement, we risk offering poorer care ... to patients from minority ethnic groups.' We could not agree more where the focus is inappropriate, but incorporated appropriately as part of a holistic programme with a view to understanding the cultural determinants of mental disorders it can add to a greater understanding and relevance of treatment provided.

Murray \& Fearon claim that the Count Me In Census 2006 has 'demonstrated that the causes [of high rates of psychosis and compulsory detention] do not lie in psychiatry', but that higher levels of compulsory admissions among Black groups are due to 'patients being referred to psychiatric units via the courts or police'. No one to our knowledge has said that the causes of higher rates of admission lie 'in psychiatry', but even if they had the census results could neither confirm nor refute this. The census was a snapshot, at best a point prevalence study. It simply does not provide such answers. The census shows that referral by the criminal justice system is one important factor among a wide range of factors, but it does not explain why second- and third-generation young Black men are 18 times more likely to be admitted to psychiatric hospital.

We believe the reasons for the high rates of admission and detention of some Black and minority ethnic groups are multifactorial and that no one explanation will suffice. However, we consider that institutional racism in mental health and in wider public services is a contributory factor. We do not want to propose simplistic explanations but the figures demand explanation. Either there is an epidemic of mental illness among certain Black groups or there are seriously worrying practices that are leading to disproportionate levels of admission. Wherever the answer lies on the spectrum between the two extremes it is essential that we find out as a matter of urgency.

We are disheartened by the way in which Professors Singh and Murray and Dr Fearon and others deflect the debate. Their 'straw man' - that psychiatrists are racist - has the unfortunate effect of taking our eyes off
† See pp. 363-366 $368-370$ and $397-$ 398 , this issue. 
the ball; all the evidence suggests that Black people and many people from other minority ethnic groups are being admitted to and detained in psychiatric hospitals either

opinion \& debate unnecessarily or at disproportionate rates. Psychiatry and psychiatrists are only one part of a complex organisational response to mental disorder; it is the (possibly) discriminatory response of that complex structure which is at issue, not the views of individual psychiatrists. We must focus on the underlying reasons, whatever those are, and try to understand the multifactorial interrelated issues which lead to the heightened admission and detention rates for some groups in society.

\section{Declaration of interest}

K.P. is Chairman and C.H. Chief Executive of the Mental Health Act Commission.

\section{References}

BHUI, K., STANSFELD, S., HULL, S., et al (2003) Ethnic variations in pathways to and use of specialist mental health services in the UK: systematic review. British Journal of Psychiatry, 182 105-116.

HEALTHCARE COMMISSION (2007) Count Me In Census 2006. Healthcare Commission. http://

www.healthcarecommission.org.uk/ nationalfindings/

nationalthemedreports/mentalhealth/ countmein/2006.cfm

MENTAL HEALTH ACT COMMISSION (1985) First Biennial Report 1983-85. Mental Health Act Commission.
PATEL, K. WINTERS, M. BASHFORD, 」, et al (2003) Engaging and Changing: Developing Effective Policy for the Care and Treatment of Black and Minority Ethnic Detained Patients. Department of Health \& National Institute for Mental Health in England.

WARNER, L., NICHOLAS, S., PATEL, K, et al (2000) National Visit 2: A Visit by the Mental Health Act Commission to 104 Mental Health and Learning Disability Units in England and Wales. Improving Care for Detained Patients from Black and Minority Ethnic Communities. Sainsbury Centre for Mental Health, Mental Health Act Commission \& University of Central Lancashire.

\section{Better mental healthcare for minority ethnic groups - moving away from the blame game and putting patients first: Commentary on ... Institutional racism in psychiatry ${ }^{\dagger}$}

Providing better mental healthcare for the Black and minority ethnic population often requires much more than the efforts of the individual clinician. Problems may range from getting the right interpreters when they are needed, for as long as they are needed, to accessing psychotherapy and social service help for refugees and asylum seekers. Most of us have little training in negotiating differences in illness models, diagnostic labels and preferred pathways to care and treatment for a multicultural society (Department of Health, 2005).

All of these difficulties and more are reflected in the literature on disparities in care between ethnic groups in the UK (Sashidharan, 2003). These problems are not the fault of clinicians but reflect the need for a concerted, coherent effort at an institutional level. Those using the institutional racism paradigm to understand disparities and develop solutions focus on systems not individuals (McKenzie, 1999). Tackling these disparities requires institutions to take responsibility for producing an environment that develops and supports sustainable, effective, ethical interventions targeted at delivering equitable services. Unfortunately, when institutions are challenged to do this they often do not take responsibility.

'We just don't believe that "institutional racism" would be a helpful label to apply - the solutions lie in the hands of individuals, not institutions' (Department of Health Media Centre, personal communication 2007). the individual and the issues are not explained by individual racism.

These problems are seen repeatedly. Suicide by African-Caribbeans who are in contact with mental health services is one example. Research in the 1990s had shown that those with a diagnosis of psychosis have a five times lower risk of self-harm and suicide (McKenzie et al, 1995) but in 2003 McKenzie et al reported that young African-Caribbeans had the same risk as British Whites. The National Confidential Inquiry has stated that clinicians in charge of the care of African-Caribbeans who have died by suicide are more likely to report that they believe this could have been prevented (Hunt et al, 2003).

We do not think it would be at all helpful to point the finger at individual clinicians. Preventing suicide is difficult and requires a wide-ranging strategy. Mental health professionals are as good as the systems that they work in and the body of knowledge they have. Practice needs to be revised as new knowledge and interventions emerge. Dealing with the issue of African-Caribbean suicides may require research, training, the production of culturally valid risk assessment tools, service development in the statutory and non-statutory sectors and a public awareness campaign. Most other reported disparities require similar in-depth analysis and an institutional response.

We all know that despite our best efforts some ethnic groups do not get equitable mental health treatment. This is backed by clinical experience and research 